\title{
Computers in providing nutrition education to osteoporotic patients: An Ardent need
}

\author{
Renu Paliwal and Aarti Sankhala
}

\begin{abstract}
With a frightening increase in the prevalence of non-communicable diseases and their high therapeutic cost it becomes indispensable that the vast pool of existing knowledge be made available to the ultimate beneficiaries with the help of most widely accepted modern technological tool i.e. via computers as they have played an excellent role in growth and development knowledge assessment tool comprised of questions on different aspects (general facts, prevalence, etiology, clinical manifestation, role of diet and exercise in the management of the disease) was framed after reviewing the literature extensively. The maximum attainable scores were then distributed into three categories (good, average and fair). The knowledge assessment tools so developed were tested for its reliability by selecting 10 disease subjects purposively and the tool was found highly reliable $(r=0.94)$. With the use of this system there was a significant increase in the knowledge of the users in males as well as in females of the disease group with a total per cent improvement of 82.98 in osteoporotic subjects. The mean pre test scores was $9.7 \pm 3.29$ and the mean post test scores were 17.75 \pm 2.57 . All the patients were falling in the fair range of knowledge and they were all shifted to the category of good after the exposure of the developed system. Hence, it can be concluded that software has definitely played a crucial role in improving the knowledge level of the users.
\end{abstract}

Key Words : Computers, Nutrition education, Non- communicable diseases

How to cite this article : Paliwal, Renu and Sankhala, Aarti (2016). Computers in providing nutrition education to osteoporotic patients: An Ardent need. Food Sci. Res. J., 7(2): 292-298, DOI : 10.15740/HAS/FSRJ/7.2/292-298. 